\title{
PERAN STRATEGI PENGAJARAN GURU DALAM RELASI ANTARA EFIKASI GURU DAN PENERIMAAN TEMAN SEBAYA TERHADAP SISWA DI SEKOLAH INKLUSIF
}

\author{
Pratiwi Widyasari* \& Annisa Ainina Novara \\ Fakultas Psikologi, Universitas Indonesia, Depok \\ *Email: pratiwi.widyasari08@ui.ac.id
}

\begin{abstract}
Abstrak
Penerimaan teman sebaya bagi anak berkebutuhan khusus pada lingkup pendidikan inklusif dianggap penting. Hal ini dikarenakan adanya kesempatan bagi mereka untuk berinteraksi bersama dengan teman-teman sebaya mereka sehingga proses belajar dan bersosialisasi dapat berjalan dengan lebih baik. Penelitian ini hendak melihat bagaimana hubungan antara efikasi guru dengan penerimaan teman sebaya terhadap siswa berkebutuhan khusus yang dimediasi oleh strategi pengajaran guru pada sekolah inklusif. Partisipan dari penelitian ini adalah 70 orang guru dan 596 murid dari 18 sekolah inklusi. Adapun alat ukur yang dipergunakan pada penelitian ini adalah The Teacher's Sense of Efficacy Scale (TSES) untuk mengukur efikasi guru, The Bender Classroom Structure Questionnaire Versi Indonesia (BCSQ_VI) untuk mengukur strategi pengajaran guru, dan Peer Acceptance Scale (PAS) untuk mengukur penerimaan siswa sebaya. Dari penelitian ini didapatkan hasil bahwa tidak ada pengaruh langsung (direct effect) yang signifikan antara efikasi guru terhadap penerimaan teman sebaya terhadap siswa berkebutuhan khusus di sekolah inklusif, $b=0,0145, t=0,3584, p=0,7212$ dan ada pengaruh tidak langsung (indirect effect) yang signifikan antara efikasi guru terhadap penerimaan teman sebaya terhadap siswa berkebutuhan khusus di sekolah inklusif, $b=0,0311, L L C I=$ 0,0083 dan $U L C l=0,0722$. Hal ini membuktikan bahwa strategi pengajaran guru memediasi penuh hubungan antara efikasi guru dan penerimaan teman sebaya terhadap siswa berkebutuhan khusus di sekiolah inklusif.
\end{abstract}

Kata kunci: penerimaan teman sebaya; strategi pengajaran; efikasi guru; inklusif

\begin{abstract}
Peer acceptance for students with Special Education Needs (SEN) in the scope of inclusive education is considered important. The reason is because there are some opportunities for them to interact with their peers which can make learning and socializing process work better. The aim of this study is to know how the relationship between teacher efficacy and peer acceptance of student with SEN is mediated by teacher's teaching strategies in inclusive schools. Participants from this study were 70 teachers and 596 students from 18 inclusive schools. The measurement tool used in this study are The Teacher's Sense of Efficacy Scale (TSES) to measure teacher efficacy, The Bender Classroom Structure Questionnaire Indonesian Version (BCSQ_VI) to measure teachers' teaching strategies, and Peer Acceptance Scale (PAS) to measure peer acceptance for student with SEN. From this study, it was found that there was no significant direct effect between teacher efficacy on peer acceptance of students with SEN in inclusive schools, $b$ $=0.0145, t=0.3584, p=0.7212$ and there was significant indirect effect between teacher efficacy toward peer acceptance of students with SEN in inclusive schools, $b=0.0311$, $L L C I=0.0083$ and $U L C I=0.0722$. This proves that the teachers' teaching strategy fully
\end{abstract}


mediates the relationship between teacher efficacy and peer acceptance of students with SEN in inclusive schools.

Keywords: peer acceptance; teacher strategy; teacher efficacy; inclusion

\section{Pendahuluan}

Pendidikan adalah hak yang dimiliki oleh setiap orang, termasuk juga anak yang memiliki kebutuhan khusus (Republik Indonesia, 2003; United Nation, 2008). Anak berkebutuhan khusus sendiri dapat diartikan sebagai anak yang berbeda dari rata-rata anak normal, bila dilihat dari aspek mental, sensoris, fisik, sosial, emosional, komunikasi, maupun kombinasi diantaranya (Mangusong, 2009). Dalam hal ini, mereka membutuhkan pendidikan dan pelayanan khusus karena mereka ditandai sebagai siswa yang berbeda dari kebanyakan siswa lainnya di beragam aspek (Hallahan \& Kauffman, 2006). Pada literatur yang sama juga ditegaskan bahwa pendidikan khusus diperlukan agar mereka menyadari potensi yang mereka miliki.

Sekolah inklusi, sebagai salah satu jenis pendidikan khusus untuk anak berkebutuhan khusus (Mangunsong, 2009) mulai banyak bermunculan dalam dekade terakhir ini (Adibsereshki \& Salehpour, 2014). Sekolah maupun kelas dengan pendidikan inklusif itu sendiri merupakan tempat dimana siswa berkebutuhan khusus diberikan kesempatan serta pelayanan untuk belajar pada situasi yang sama seperti teman-temannya yang tidak memiliki kebutuhan khusus (Adibsereshki \& Salehpour, 2014, Darma \& Rusyidi, 2015) daripada ditempatkan pada sekolah khusus (Kurniawati, Minnaert, Mangunsong, \& Ahmed, 2012).

Dengan melihat kelebihan serta kebermanfaatan yang diberikan oleh sekolah inklusi, keberadaan sekolah inklusi di tengah-tengah masyarakat menjadi sangat penting. Namun demikian, dari 1,6 juta anak berkebutuhan khusus di Indonesia, seperti yang dilansir oleh Badan Pusat Statistik (BPS), hanya sekitar 18 persen yang sudah merasakan layanan pendidikan inklusi (Maulipaksi, 2017). Hal inilah yang membuat kajian serta penelitian di area inklusivitas menjadi sesuatu yang penting untuk terus dilakukan.

Dalam situasi pembelajaran yang inklusif, siswa berkebutuhan khusus mendapatkan manfaat pada sisi kemampuan akademis maupun sosial melalui proses mereka pada saat berbagi pengalaman (Adibsereshki \& Salehpour, 2014). Hal ini tidak terlepas dari peranan penting dari kelompok teman sebaya pada perkembangan manusia karena mereka memenuhi beberapa kebutuhan dasar, seperti kebutuhan untuk menjadi bagian dalam sebuah kelompok dan berinteraksi secara sosial, serta kebutuhan untuk mengembangkan identitas personal (Berns, 2010). Sebuah penelitian juga menunjukkan bahwa semakin tinggi dukungan sosial dari teman sebaya yang diterima oleh siswa tuna rungu maka akan semakin tinggi pula penyesuaian diri mereka di sekolah inklusif (Hasan \& Handayani, 2014). Kelompok teman sebaya dianggap sebagai agen sosialisasi yang signifikan untuk berkontribusi dalam memenuhi kontribusi di luar pengaruh dari keluarga dan sekolah (Berns, 2010).

Penerimaan teman sebaya sendiri memiliki arti yaitu sejauh mana individu mampu diterima secara sosial oleh kelompok penerimaan teman sebayanya (Berk, 2007). Penerimaan tersebut biasanya terjadi berdasarkan pengakuan akan kesamaan dari kelompok penerimaan teman sebaya (Cook \& Semmel, 1999). Dalam hal ini, penerimaan teman sebaya dan pelibatan sosial sejak dini dapat berperan sebagai katalis untuk perkembangan kompetensi sosial (Küçüker, Erdoğan, \& Çürük, 2014). 
Level penerimaan sosial seorang anak dari teman-teman di kelasnya adalah aspek yang paling sering untuk diteliti pada area hubungan teman sebaya di kelas (Hughes, Im, \& Wehrly, 2014) dan juga menjadi topik di berbagai penelitian di area pendidikan inklusif (Adibsereshki \& Salehpour, 2014). Oleh karena itu, penerimaan teman sebaya dipertimbangkan sebagai hal yang penting untuk mendapatkan hasil yang positif pada anak-anak berkebutuhan khusus dalam area pendidikan inklusif anak usia dini (Küçüker dkk., 2014) dan salah satu kunci utama yang dapat memastikan kesuksesan dari pelaksanaan pendidikan inklusif (Gökbulut, Gökbulut, \& Yeniasır, 2017). Küçüker, dkk. (2014) juga menambahkan bahwa memfasilitasi adanya penerimaan teman sebaya pada anak berkebutuhan khusus menjadi hal yang penting untuk menghasilkan perkembangan yang positif dari program pembelajaran pada anak-anak.

Dari kajian yang telah dilakukan, ditemukan bahwa guru memegang peranan penting dalam kehidupan siswa di dalam sebuah sekolah (Murray \& Pianta, 2007) dan hal tersebut sangat tergantung dari bagaimana guru mengatur peran mereka sebagai pendukung bagi siswasiswa berkebutuhan khusus ini (Sigstad, 2017). Terlepas dari apakah seorang guru membutuhkan pelatihan pada area pendidikan khusus, mereka diharapkan dapat mengedukasi siswa berkebutuhan khusus dimana mereka juga dituntut untuk dapat menghadapi siswa dengan berbagai karakteristik. Dalam hal ini, setiap guru harus mengeluarkan usaha agar kebutuhan setiap peserta didik terpenuhi, meski mungkin kebutuhan tersebut berbeda dari rata-rata siswa yang ada di kelas, sehingga daya fleksibilitas, adaptasi, serta perhatian khusus diharapkan dapat muncul dalam diri setiap guru (Hallahan \& Kauffman, 2006). Guru harus sangat menyadari akan tanggung jawabnya dalam menyediakan instruksi yang cocok untuk siswa dengan kebutuhan khusus (Mastro- prieri \& Scruggs, 2000) sehingga strategi mengajar menjadi hal yang dibutuhkan.

Strategi Pengajaran dapat diartikan sebagai sebuah kegiatan pembelajaran yang dipilih oleh guru untuk melaksanakan proses belajar (Mangunsong, 2009). Strategi pengajaran merupakan praktik pengajaran yang memfasilitasi pemberian materi pembelajaran dalam pendidikan inklusi (Bender, 1992). Adapun kegiatan belajar yang dipilih adalah kegiatan yang paling efektif serta efisien dalam memberikan pengalaman belajar yang diperlukan agar tujuan instruksional yang telah dibuat dapat tercapai (Mangunsong, 2009). Guna mengoptimalkan proses pembelajaran yang mengikutsertakan siswa berkebutuhan khusus di dalamnya, guru harus menciptakan komunitas belajar yang dapat membuat siswa berkebutuhan khusus menjadi bagian dari proses yang terjadi di dalam kelas tersebut. Guru juga harus membuat rencana-rencana belajar yang mengacu pada desain yang umum/ universal, termasuk pula di dalamnya tujuan serta sasaran yang bervariasi dalam tingkat kompleksitasnya, agar kemajuan dari semua peserta didik dapat terlihat (Turnbul, Turnbul, Wehmeyer, \& Shogren, 2013).

Praktik strategi pengajaran yang efektif pada pendidikan inklusif dipengaruhi oleh beberapa faktor, salah satunya adalah teacher efficacy atau efikasi guru (David \& Kuyini, 2012). Menurut Tschannen-Moran dan Hoy (2001), efikasi guru memiliki potensi untuk mempengaruhi lingkungan di sekitar guru seperti misalnya penggunaan praktik pengajaran yang dilakukan di dalam kelas. Guru yang memiliki efikasi diri terhadap kemampuannya akan memiliki potensi untuk melakukan variasi pembelajaran. Efikasi guru sendiri didefinisikan sebagai keyakinan guru terhadap kemampuan dirinya mengatur dan melaksanakan tindakan yang diperlukan untuk mencapai keberhasilan dalam tugas pengajaran tertentu di suatu konteks (Tschannen-Moran \& Hoy, 2001). 
Proses pengajaran dapat guru lakukan dengan baik apabila guru memiliki kepercayaan diri mengenai kemampuannya dalam mengajar. Guru dengan efikasi yang tinggi percaya apabila mereka melakukan usaha yang lebih besar, mereka mampu untuk menangani semua siswa, bahkan siswa yang paling sulit (Elsami \& Fatani, 2008). Selain itu, guru yang memiliki efikasi yang tinggi akan menggunakan berbagai variasi metode pengajaran agar mampu menyesuaikan dengan kebutuhan siswanya (Guskey, 1988). Berdasarkan hal tersebut, keyakinan guru mengenai kemampuannya bisa menjadi penentu bagi guru melakukan aktivitas pembelajaran.

Terkait efikasi yang dimiliki oleh guru, David dan Kuyini (2012) menyebutkan bahwa meskipun terdapat peran yang positif dari sikap guru dan juga efikasi guru terhadap kesuksesan pelaksanaan pendidikan inklusif bagi siswa dengan kebutuhan khusus, namun faktorfaktor ini harus dapat diterjemahkan ke dalam praktik pembelajaran di kelas yang dapat memberikan dukungan langsung kepada siswa di kelas. Dalam hal ini, dapat dikatakan bahwa efikasi guru tidak secara langsung memiliki peranan terhadap dukungan yang didapatkan oleh siswa di dalam kelas.

Dengan melihat dinamika hubungan yang terjadi, dimana efikasi guru memiliki peran dalam meningkatkan strategi pengajaran pada guru di kelas, dan juga strategi pengajaran yang juga memiliki hubungan terhadap penerimaan teman sebaya pada anak berkebutuhan khusus di kelas inklusi, maka peneliti ingin melihat bagaimana hubungan antara efikasi guru dalam mengajar di kelas inklusi dengan penerimaan teman sebaya pada anak berkebutuhan khusus, yang dimediasi oleh strategi pengajaran.

\section{Metode Penelitian}

Partisipan. Pada penelitian ini, peneliti menggunakan guru dan murid sebagai partisipan. Hal ini dipilih karena peneliti ingin melihat hubungan antara efikasi guru, strategi pengajaran yang digunakan oleh guru, dan penerimaan teman sebaya siswa yang tidak memiliki kebutuhan khusus pada temannya di kelas yang berkebutuhan khusus. Adapun sekolah inklusi yang menjadi partisipan dalam penelitian ini adalah 18 sekolah dasar inklusi, baik itu sekolah negeri maupun sekolah swasta yang berada pada wilayah Jakarta, Depok, dan Bogor.

Karakteristik partisipan guru antara lain merupakan guru yang melakukan kontak langsung dengan siswa berkebutuhan khusus di kelas, merupakan wali kelas dan mengajar di kelas inklusi, bukan merupakan guru pendamping khusus, dan bukan termasuk guru bidang studi khusus, seperti misalnya guru agama atau guru olahraga. Hal ini dimaksudkan karena guru yang mengajar di kelas lebih terlibat dan memiliki wewenang serta tanggung jawab yang lebih besar dalam proses pembelajaran di kelas.

Karakteristik partisipan siswa antara lain merupakan siswa reguler (tidak memiliki kebutuhan khusus). Siswa reguler dipilih karena peneliti ingin melihat penerimaan teman sebaya siswa reguler terhadap siswa berkebutuhan khusus di kelas inklusi. Kriteria lainnya adalah merupakan siswa kelas 4,5 , dan 6 yang di dalam kelasnya terdapat minimal 1 siswa berkebutuhan khusus. Peneliti juga memilih siswa dengan tingkat intelektual yang beragam untuk menghindari pengaruh intelektualitas terhadap penerimaan teman sebaya. Proporsi antara siswa dan siswi juga diseimbangkan untuk menghindari pengaruh gender pada penerimaan siswa.

Dari gambaran partisipan pada penelitian ini, diketahui bahwa jumlah partisipan siswa laki-laki adalah 304 siswa $(47,7 \%)$ dan partisipan siswi perempuan adalah 332 siswa $(52,3 \%)$. Untuk partisipan guru, laki-laki berjumlah 16 orang $(22,9 \%)$ dan perempuan 54 orang $(77,1 \%)$, berusia kurang dari 30 tahun 14 
Tabel 1. Gambaran demografi partisipan

\begin{tabular}{lcc}
\hline \multicolumn{1}{c}{ Karakteristik } & Jumlah $(\mathrm{N})$ & Presentase $(\%)$ \\
\hline Jenis Kelamin Siswa & 304 & 47.7 \\
Laki-laki & 332 & 52.3 \\
Perempuan & & \\
Jenis Kelamin Guru & 16 & 22.9 \\
$\quad$ Laki-laki & 54 & 77.1 \\
Perempuan & & \\
Usia Guru & 14 & 20 \\
< 30 tahun & 44 & 62.9 \\
$30-50$ tahun & 11 & 15.7 \\
$>$ 50 tahun & 1 & 1.4 \\
Tidak ada data & & \\
Pendidikan Guru & 2 & 2.9 \\
D3 & 64 & 91.4 \\
S1 & 3 & 4.3 \\
S2 & 1 & 1.4 \\
Tidak ada data & & \\
\hline
\end{tabular}

orang $(20 \%), 30-50$ tahun 44 orang $(62,9 \%)$ dan lebih dari 50 tahun 11 orang $(15,7 \%)$, berpendidikan D3 2 orang $(2,9 \%)$, S1 64 orang $(91,4 \%)$ dan S2 3 orang $(4,3 \%)$ (lihat tabel 1$)$.

Desain. Penelitian ini termasuk ke dalam penelitian non eksperimental, merupakan penelitian kuantitatif dikarenakan data yang akan diambil merupakan data numerik yang akan diolah dengan menggunakan perhitungan statistik, dan korelasional dikarenakan penelitian ini ingin melihat keterkaitan antara dua atau lebih variabel.
Prosedur. Terdapat 70 kelas yang diukur, terdiri dari 70 guru dan 596 murid. Setiap unit kelas terdiri dari satu guru utama dan 6-11 siswa, dimana nilai guru akan dikorelasikan dengan nilai rerata siswa pada kelas tersebut. Responden siswa dipilih secara acak dari tiap kelasnya dengan proporsi sebanyak $30 \%$ dari jumlah keseluruhan siswa di kelas tersebut. Adapun jenjang kelas yang diteliti yakni kelas 4, 5, dan 6 karena siswa diyakini sudah mampu menentukan pilihannya dalam berteman dan juga telah mampu mengerjakan kuesioner yang berbentuk self report. 
Peneliti menggunakan teknik nonprobability sampling dalam pengambilan sampel karena jumlah populasi tidak diketahui secara lengkap sehingga dalam pengambilan sampel pada penelitian ini tidak semua individu yang berada dalam populasi memiliki kesempatan untuk menjadi sampel penelitian. Teknik nonprobability sampling yang digunakan adalah convenience sampling dimana sampel dipilih berdasarkan ketersediaan dan keinginan dari orang tersebut untuk ikut serta dalam penelitian ini.

Terdapat tiga alat ukur yang dipergunakan dalam penelitian ini, yaitu Teacher's Sense of Efficacy Scale (TSES) untuk mengukur efikasi guru (Mariyati, 2012), The Bender Classroom Structure Questionnaire Versi Indonesia (BCSQ_VI) untuk mengukur strategi pengajaran guru (Sihombing, 2014), dan Peer Acceptance Scale (PAS) untuk mengukur penerimaan siswa sebaya (Rahmayati, 2013).

Alat ukur TSES dan BCSQ_VI telah diujicobakan kepada 61 guru $\overline{d i} 6$ sekolah. Sekolah yang dipilih sebagai tempat uji coba merupakan sekolah negeri dan swasta yang menerima siswa berkebutuhan khusus untuk masuk di kelas inklusi. Karakter guru yang menjadi partisipan pada uji coba ini antara lain merupakan guru kelas 1-6 SD yang dalam kelasnya terdapat minimal 1 siswa berkebutuhan khusus. Alat ukur PAS telah diujicobakan kepada 180 siswa dari 6 sekolah. Karakter siswa yang menjadi partisipan pada uji coba antara lain merupakan siswa kelas 4-6 SD dan terdapat minimal 1 siswa berkebutuhan khusus di kelasnya.

Teacher's Sense of Efficacy Scale (TSES) merupakan alat ukur efikasi guru terhadap pendidikan inklusif. TSES disusun oleh Tschannen-Moran dan Hoy (2001) dan telah diterjemahkan dan diadaptasi oleh Mariyati (2012). Dalam alat ukur ini, terdapat tiga dimensi dari efikasi guru, diantaranya efficacy in instructional strategies, efficacy in classroom manage- ment, dan efficacy in student engagement (Tschannen-Moran \& Hoy 2001). TSES memiliki 20 item dengan enam poin skala Likert yakni "sangat tidak sesuai", "agak tidak sesuai", "tidak sesuai", "agak sesuai", "sesuai", dan "sangat sesuai". Setiap jawaban yang dipilih akan diubah menjadi angka dalam rentang 1 hingga 6 . Berdasarkan skala tersebut, akan didapatkan skor total dari efikasi guru. Semakin tinggi nilai yang didapat menandakan bahwa semakin tinggi tingkat keyakinan yang dimiliki oleh guru tersebut untuk mengajar di kelas inklusif. Nilai uji reliabilitas tryout TSES berdasarkan koefisien Alpha-Cronbach sebesar 0,814. Contoh item pada alat ukur TSES antara lain pada dimensi efficacy in instructional strategies yaitu "saya merasa perlu untuk mengubah strategi pengajaran bagi siswa tertentu ketika ia tidak memahami materi yang saya ajarkan", pada dimensi efficacy in classroom management yaitu "saya merasa perlu membahas peraturan tentang apa yang boleh dan tidak boleh dilakukan siswa di kelas", dan pada dimensi efficacy in student engagement yaitu "siswa di kelas terlihat bersemangat".

BCSQ VI merupakan alat ukur untuk menilai penggunaan strategi pengajaran guru yang dapat memfasilitasi pendidikan inklusif, dikonstruksi oleh Bender (1992) dan telah diadaptasi oleh Sihombing (2014). Alat ukur BCSQ_VI terdiri atas 40 item yang mengukur strategi pengajaran guru dalam dimensi strategi individual, strategi kognitif, dan total seluruh strategi. Nilai uji reliabilitas tryout BCSQ_VI menggunakan koefisien AlphaCronbach adalah 0,73 . Pada alat ukur BCSQ_VI, setiap item memiliki empat rentang skala Likert yang menggambarkan frekuensi yakni "sangat jarang", "jarang", "sering", dan "hampir selalu". Setiap jawaban yang dipilih akan diubah menjadi angka dalam rentang 1 hingga 4 . Berdasarkan skala tersebut, akan didapatkan skor total dari strategi pengajaran inklusi. Contoh item pada alat ukur 
BCSQ_VI pada dimensi strategi individual yaitu "secara rutin saya menggunakan tingkat instruksi yang beragam bagi siswa berkebutuhan khusus di kelas saya", pada dimensi strategi kognitif yaitu "siswa diajari menggunakan bahasanya sendiri untuk memudahkannya memahami suatu instruksi", dan pada dimensi total seluruh strategi yaitu "saya mendorong siswasiswa mengulas kembali tugas setelah saya mengembalikannya kepada mereka".

PAS merupakan alat ukur yang dikonstruksi oleh Piercy, Wilton, dan Townsend (2002) yang telah diadaptasi ke dalam bahasa Indonesia oleh Rahmayati (2013) untuk mengukur penerimaan teman sebaya. Alat ukur PAS kemudian dikembangkan oleh peneliti menjadi 10 item pertanyaan dengan tiga rentang skala Likert mulai dari skala 1 "tidak mau", skala 2 "mau dengan terpaksa", dan skala 3 "mau dengan senang hati". Hasil pengujian kembali pada 180 siswa menunjukkan reliabilitas alat ukur PAS adalah sebesar .895. Bila nilai yang didapatkan oleh partisipan semakin tinggi, hal ini menandakan bahwa tingkat penerimaannya akan teman-teman berkebutuhan khusus di kelas juga semakin tinggi. Contoh item pada alat ukur PAS yaitu "apakah kamu mau berbagi rahasia dengan siswa tersebut?".

Setelah dipastikan bahwa ketiga alat ukur dapat dipergunakan dalam pengambilan data, peneliti lalu menghubungi sekolah-sekolah inklusif yang berada di wilayah Jakarta, Depok, dan Bogor untuk bertanya mengenai prosedur penelitian di sekolah tersebut. Selanjutnya peneliti mengirimkan surat permohonan ijin penelitian kepada sekolah. Proses pengambilan data dilakukan selama satu bulan. Untuk pengisian kuesioner yang dilakukan oleh guru, peneliti mendampingi atau menitipkan kepada kepala sekolah maupun perwakilan dari guru kelas dikarenakan keterbatasan waktu yang dimiliki oleh guru di sekolah untuk mengisi kuesioner pada saat peneliti hadir di sekolah. Untuk pengisian kuesioner yang dilakukan oleh siswa, prosedur pelaksanaannya adalah dengan menggunakan aplikasi pengacak nomor. Siswa yang dipilih menjadi partisipan yaitu yang berdasarkan nomor absen yang keluar. Pemilihan partisipan juga disesuaikan dengan proporsi gender. Setelah mendapatkan nama partisipan siswa, peneliti mengelompokkan partisipan berdasarkan kelas. Setiap kelompok partisipan didampingi oleh satu orang fasilitator untuk mengisi alat ukur PAS. Partisipan diminta untuk membaca instruksi yang tertera di dalam kuesioner, lalu fasilitator akan berdiskusi mengenai siapa yang menjadi siswa berkebutuhan khusus di kelas partisipan. Fasilitator lalu meminta partisipan untuk menjawab pertanyaan pada kuesioner berdasarkan siswa berkebutuhan khusus tersebut.

Teknik Analisis. Peneliti menggunakan SPSS versi 20 sebagai alat untuk melakukan analisis data. Pada penelitian ini, dilakukan analisis statistik deskriptif untuk mengetahui nilai rerata serta standar deviasi dari variabelvariabel yang diteliti. Pearson correlation juga dipergunakan untuk melihat korelasi antar variabel. Untuk menguji model mediasi (simple mediation) yang diajukan oleh peneliti, dipergunakan perhitungan regresi dengan bantuan program PROCESS dari Hayes (2013). Teknik analisis ini mampu melihat bagaimana peran variabel mediator terhadap kekuatan hubungan antara variabel bebas dan variabel terikat.

\section{Hasil Penelitian}

Berdasarkan penelitian yang telah dilakukan, setelah melakukan pengambilan data, dilakukan uji reliabilitas kembali dari alat ukur yang dipergunakan di dalam penelitian ini. Berdasarkan hasil uji reliabilitas alat ukur dengan menggunakan Alpha-Cronbach, nilai koefisien dari TSES adalah sebesar 0,657, BCSQ_VI sebesar 0,779, dan PAS sebesar 0,749. 
Tabel 2. Hasil statistika deskriptif dan inter-korelasi antara variabel penelitian

\begin{tabular}{lccccc}
\hline \multicolumn{1}{c}{ Variabel } & $M$ & SD & 1 & 2 & 3 \\
\hline Efikasi Guru & 103,73 & 6,07 & - & & \\
Strategi Pengajaran & 121,94 & 8,81 & $0,319^{* *}$ & - & \\
Penerimaan Teman Sebaya & 14,54 & 1,99 & 0,138 & $0,309^{* *}$ & - \\
\hline
\end{tabular}

ket. ${ }^{*} p<.05 ;{ }^{* \star} p<01 ;{ }^{* \star *} p<.001$

Tabel 3. Analisis Mediasi antara Variabel Penelitian ke Penerimaan Teman Sebaya

\begin{tabular}{lcccccc}
\hline & $\beta$ & $\mathrm{SE}$ & $\mathrm{t}$ & $\mathrm{p}$ & $\mathrm{LLCl}$ & $\mathrm{ULCl}$ \\
\hline Efikasi Guru (IV) & 0,0145 & 0,0403 & 0,3584 & 0,7212 & $-0,0660$ & 0,0949 \\
Strategi Pengajaran & 0,0670 & 0,0278 & 2,4119 & 0,0186 & 0,0115 & 0,1224 \\
(Mediasi) & & & & & & \\
Indirect Effect & 0,0311 & 0,0152 & & & 0,0083 & 0,0722
\end{tabular}

$F(1,68)$

Dari olah data, didapatkan hasil bahwa efikasi guru $(M=103,73, S D=$ $6,07)$ dan strategi pengajaran $(M=$ 121,94, $S D=8,81)$ memiliki korelasi yang positif dan signifikan, $r(68)=0,319, p<$ 0,05 , two tails. Demikian halnya dengan strategi pengajaran $(M=121,94, S D=$ $8,81)$ dengan penerimaan teman sebaya $(M=14,54, S D=1,99)$ juga memiliki korelasi yang positif dan signifikan, $r(68)$ $=0,309, \mathrm{p}<0,05$, two tails. Namun demikian, efikasi guru $(M=103,73, S D=$ $6,07)$ dan penerimaan teman sebaya $(M$ $=14,54, S D=1,99)$ tidak memiliki korelasi yang signifikan, $r(68)=0,138, p$ $>0,05$, two tails (lihat tabel 2).

Selanjutnya, untuk menjawab hipotesis utama dalam penelitian ini, peneliti melakukan analisis regresi dengan mediasi untuk melihat peran strategi pengajaran guru dalam relasi antara sikap guru dan penerimaan teman sebaya terhadap siswa di sekolah inklusif dengan menggunakan bantuan perangkat lunak Process. Berdasarkan hasil perhitungan data, dapat diketahui bahwa strategi pe- ngajaran guru memiliki pengaruh yang signifikan terhadap penerimaan teman sebaya terhadap siswa di sekolah inklusif, $b=0,0670, t=2,4119, p<0,05$. Sementara itu, tidak ada pengaruh langsung (direct effect) yang signifikan antara efikasi guru terhadap penerimaan teman sebaya terhadap siswa di sekolah inklusif, $b=0,0145, t=0,3584, p=0,7212$. Sebaliknya, ada pengaruh tidak langsung (indirect effect) yang signifikan antara efikasi guru terhadap penerimaan teman sebaya terhadap siswa di sekolah inkIusif, $b=0,0311, L L C I=0,0083$ dan $U L C$ I $=0,0722$ (Lihat tabel 3).

Dengan demikian, dapat dikatakan bahwa hasil penelitian ini membuktikan hipotesis penelitian yaitu strategi pengajaran guru memediasi penuh (full mediated) hubungan antara efikasi guru dan penerimaan teman sebaya terhadap siswa di sekolah inklusif.

\section{Diskusi}

Berdasarkan penelitian yang telah dilakukan, diketahui bahwa terdapat hu 
bungan yang positif dan signifikan antara strategi pengajaran yang dilakukan oleh guru di dalam kelas dengan penerimaan teman sebaya pada siswa berkebutuhan khusus. Dalam hal ini, strategi yang diterapkan oleh guru mampu membuat relasi serta penerimaan siswa di dalam kelas menjadi lebih kuat. Dalam bukunya, Mangunsong (2011) mengatakan bahwa terdapat beberapa strategi pengajaran yang dapat diterapkan oleh guru pada pelaksanaan pendidikan inklusif, salah satunya yaitu peer tutoring. Dalam peer tutoring, siswa mendapatkan bantuan dari temannya, baik antara siswa normal kepada siswa berkebutuhan khusus, maupun antar siswa berkebutuhan khusus yang berbeda usia. Dalam hal ini, siswa tanpa kebutuhan khusus dapat menjadi model bagi temannya yang berkebutuhan khusus. Tutoring sendiri dapat menjadi cara yang sangat ampuh dalam meningkatkan perfoma siswa di dalam kelas dan juga dapat sangat membantu dalam mengatasi beragam kebutuhan belajar yang terdapat pada kelas inklusif (Mastroprieri \& Scruggs, 2000).

Pada literatur yang sama juga disebutkan bahwa salah satu strategi pengajaran di dalam kelas inklusif yang dapat meningkatkan prestasi serta hubungan sosial pada peserta didik dengan beragam karakteristik adalah cooperative learning. Dengan ciri-ciri dari metode pembelajaran yang dimiliki oleh strategi pengajaran di atas, para peserta didik mendapatkan kesempatan untuk lebih banyak berinteraksi dengan teman-temannya di kelas. Mastroprieri dan Scruggs (2000) menekankan bahwa dalam hal ini, teman sebaya dapat diajarkan beragam strategi yang dapat mengarahkan keterlibatan siswa untuk saling membantu selama kegiatan di kelas maupun di sekolah. Ditambahkan pula bahwa temanteman di kelas adalah kunci dari penerimaan sosial, dan pada situasi yang tepat dapat menyediakan bantuan yang diperlukan untuk membantu siswa berkebutuhan khusus agar lebih dapat di- terima di dalam kelas. Dalam hal ini, program yang dapat mendorong interaksi yang menyenangkan diantara siswa di kelas inklusi, baik untuk siswa berkebutuhan khusus maupun siswa yang tidak memiliki kebutuhan khusus, dapat meningkatkan keterlibatan dan penerimaan siswa dalam beraktivitas di kelas (Bricker, 2000). Instruksi yang efektif dimulai pada saat guru secara sengaja menciptakan lingkungan belajar yang membuat siswa saling belajar untuk menghormati satu sama lain dan menghargai perbedaan yang dimiliki antar individu (Turnbul dkk., 2013).

Sehubungan dengan relasi antara efikasi guru dan juga strategi pengajaran yang dilakukan oleh guru di kelas, pada penelitian ini ditemukan bahwa terdapat hubungan diantara keduanya. Hal ini menandakan bahwa ketika guru memiliki kepercayaan dalam mengajar di situasi inklusif, keadaan tersebut akan mendorong guru untuk meningkatkan strategi ataupun teknik pengajaran yang ia lakukan di dalam kelas. Temuan ini selaras dengan apa yang dikatakan Cruickshank, Bainer, dan Metcalf (1995) yang menyebutkan bahwa guru dapat mencapai kesuksesan dalam melakukan proses pengajaran apabila ia memiliki kepercayaan atas kemampuannya untuk mengajar.

Penelitian ini juga menemukan bahwa hubungan antara efikasi guru terhadap penerimaan teman sebaya pada siswa berkebutuhan khusus di sekolah inklusi tidak bersifat langsung. Dalam penelitiannya, David dan Kuyini (2012) juga menemukan bahwa efikasi yang dimiliki guru tidak memengaruhi tingkat penerimaan dari siswa berkebutuhan khusus. Secara lebih mendalam, disebutkan bahwa tingkat penerimaan siswa lebih dapat diprediksi dari bagaimana guru menerapkan sistem pengajaran di dalam kelas. Dalam hal ini, keyakinan guru dalam mengajar pada kelas inklusi, yang diperlihatkan pada kegiatan proses belajar di kelas seperti pengunaan strategi belajar yang tepat, dapat mendukung pe 
laksanaan pendidikan inklusif yang berdampak pada penerimaan siswa berkebutuhan khusus oleh teman-temannya di kelas.

\section{Kesimpulan}

Dari penelitian yang telah dilakukan, didapatkan hasil bahwa strategi mengajar yang diterapkan oleh guru di kelas inklusif mampu menjembatani dinamika hubungan antara efikasi yang dimiliki oleh guru dengan penerimaan siswa yang tidak memiliki kebutuhan khusus terhadap temanteman mereka di kelas yang memiliki kebutuhan khusus.

Limitasi dan Saran. Dengan melihat proses penelitian yang telah dilakukan, terdapat beberapa limitasi serta saran yang dapat dilakukan untuk penelitian lanjutan. Dalam hal pengambilan data untuk aspek penerimaan teman sebaya, pada penelitian ini yang dipergunakan adalah penilaian dari siswa di kelas terkait seberapa baik penerimaan mereka terhadap teman-teman mereka yang memiliki kebutuhan khusus. Untuk penelitian selanjutnya, dapat dilakukan pengambilan data dengan metode observasi (Küçüker dkk., 2014; Adibsereshki \& Salehpour, 2014). Hal ini dimaksudkan karena dengan metode observasi ketika siswa bermain di kelas, akan didapatkan gambaran yang lebih kaya dan rinci terkait interaksi sosial serta status sosial dari siswa yang tidak memiliki kebutuhan khusus maupun siswa berkebutuhan khusus (Küçüker dkk., 2014). Selain itu, Küçüker dkk. (2014) juga menambahkan bahwa penilaian dari guru juga dapat dilakukan guna memperlengkapi data tentang penerimaan siswa di kelas,

Sehubungan dengan pengambilan data yang berhubungan dengan guru yang pada penelitian ini menggunakan teknik survei berupa pemberian kuesioner dengan metode inventori diri (self-report), dalam penelitian selanjutnya juga dapat diperlengkapi dengan metode observasi, terutama berkaitan dengan strategi guru dalam mengajar.
Berkaitan dengan pemilihan subyek penelitian, penelitian ini lebih difokuskan pada siswa berkebutuhan khusus, terlepas dari jenis kebutuhan khusus yang mereka miliki. Studi yang dilakukan oleh Küçüker dkk. (2014) menemukan bahwa anak yang lebih dapat diterima pada lingkungan sosialnya adalah anak-anak yang memiliki kemampuan sosial yang lebih baik daripada anak dengan disabilitas intelektual. Hal ini juga ditegaskan oleh penelitian yang dilakukan oleh Adibsereshki dan Salehpour (2014) yang mengatakan bahwa tipe dari disabilitas memiliki peran yang signifikan pada tingkat penerimaan teman sebaya pada siswa dengan kebutuhan khusus. Selain itu, tingkat keparahan dari kebutuhan khusus siswa juga turut dipandang sebagai faktor yang membentuk sikap seorang guru untuk melibatkan siswa berkebutuhan khusus (Cassady, 2011; Subban \& Sharma, 2005; Hastings \& Oakford, 2003). Oleh karena itu, pada penelitian selanjutnya dapat ditelaah lebih lanjut pada populasi anak berkebutuhan khusus dengan jenis kebutuhan khusus serta tingkat keparahan yang lebih spesifik.

Dalam beberapa penelitian, juga ditemukan bahwa jenis kelamin dari anak berkebutuhan khusus juga dapat menjadi faktor yang memperkuat apakah anak tersebut akan lebih dapat diterima pada lingkungan sosialnya. (Adibsereshki \& Salehpour, 2014; Gökbulut dkk., 2017). Merujuk pada hal tersebut, perlu juga dikaji lebih jauh tentang bagaimana dinamika hubungan antar variabel yang diajukan dalam penelitian ini bila ditinjau dari jenis kelamin partisipan siswa lakilaki maupun perempuan.

Terkait dengan data demografis lainnya yang berhubungan dengan guru dapat pula dieksplorasi dengan lebih mendalam. Cook, Tankersley, Cook, dan Landrum (2000) menyebutkan bahwa tingkat pengalaman mengajar di kelas inklusif berasosiasi dengan lebih banyaknya perhatian yang diberikan kepada siswa berkebutuhan khusus. Dalam sum 
ber yang sama juga dituliskan bahwa salah satu strategi yang diberikan untuk meningkatkan sikap guru di kelas inklusif, yang pada akhirnya akan berhubungan dengan interaksi antara guru dan siswa, adalah menempatkan siswa berkebutuhan khusus pada kelas yang diajar oleh guru yang lebih banyak memiliki pengalaman mengajar dalam kelas inklusif. Merujuk kepada hal tersebut, maka pada penelitian lanjutan dapat dilihat bagaimana faktor pengalaman mengajar guru pada pendidikan inklusi mempengaruhi sikap maupun usaha-usaha yang dikeluarkannya, termasuk strategi pengajaran yang diterapkan, pada saat mengajar siswa berkebutuhan khusus di dalam kelas.

\section{Daftar Pustaka}

Adibsereshki, N., \& Salehpour, Y. (2014). Peer acceptance of students with and without inclusion experience towards students with special needs in unisex schools of Tehran. Education 3-13: International Journal of Primary, Elementary and Early Years Education, 42(6), 1-14. doi: 10.1080/03004279.2012.745890.

Bender, W. N. (1992). The bender classroom structure questionnaire: $A$ tool for placement decision and evaluation of mainstream learning environment. Intervention in School and Clinic, 27(5), 307-312. doi: 10.1177/105345129202700509.

Berk, L. E. (2007). Developmental through the lifespan $\left(4^{\text {th }}\right.$ ed.). New York: Pearson Education, Inc

Berns, R. M. (2010). Child, family, school, community: Socialization and support ( $8^{\text {th }}$ ed.). Belmont: Wadsworth Cengage Learning.

Bricker, D. (2000). Inclusion: How the scene has changed. Topics in Early Childhood Special Education, 20, 14-19. Doi: 10.1177/027112140002000103
Cassady, J. M. (2011). Teachers' attitudes toward the inclusion of students with autism. Electronic Journal for Inclusive Education 2(7).

Cook, B. G., \& Semmel, M. I. (1999). Peer acceptance of included students with disabilities as a function of severity of disability and classroom composition. The Journal of Special Education, 33(1), 50-61. doi: 10.1177/002246699903300105.

Cook, B. G., Tankersley, M., Cook, L., \& Landrum, T. (2000). Teachers attitudes toward their included students with disabilities. Exceptional Children, 67, 115-135. doi: $10.1177 / 001440290006700108$.

Cruickshank, Bainer \& Metcalf. (1995). The Act of Teaching. New York: McGraw-Hill, Inc.

Darma, I. P., \& Rusyidi, B. (2015). Pelaksanaan sekolah inklusi di Indonesia. Prosiding Penelitian dan Pengabdian kepada Masyarakat, 2(2).

David, R., \& Kuyini, A. B. (2012). Social inclusion: teachers as facilitators in peer acceptance of students with disabilities in regular classrooms in Tamil Nadu, India. International Journal of Special Education, 27(2).

Elsami, Z. R., \& Fatani, A. (2008). Teachers' sense of self-efficacy, english proficiency, and instructional strategies: a study of nonnative EFL teachers in Iran. Teaching English as a Second or Foreign Language, 11(4).

Gökbulut, Ö. D., Gökbulut, B., \& Yeniasır, M. (2017). Social acceptance of students with special needs from peer viewpoint. Eurasia Journal of Mathematics, Science and Technology Education, 13(11), 7287-7294. doi: 10.12973/ejmste/79592.

Guskey, T. R. (1988). Teacher efficacy, self-concept, and attitudes toward the implementation of instructional innovation. Teaching and Teacher Education, 4(1), 63-69. doi: 10.1016/0742-051X(88)90025-X. 
Hallahan, D. P., \& Kauffman. (2006). Exceptional learners: An introduction to special education (10 th ed.). Boston: Allyn and Bacon.

Hasan, S. F., \& Handayani, M. M. (2014). Hubungan antara dukungan sosial teman sebaya dengan penyesuaian diri siswa tunarungu di sekolah inklusi. Jurnal Psikologi Pendidikan dan Perkembangan, 3(2), 128-135.

Hastings, R. P., \& Oakford, S. (2003). Student teachers' attitudes towards the inclusion of children with special needs. Educational Psychology, 23(1), 87-94. doi: 10.1080/01443410303223

Hayes, A. F. (2013). Introduction to mediation, moderation, and conditional process analysis: $A$ regressionbased approach. New York: The Guilford Press.

Hughes, J. N., Im, M. H., \& Wehrly, S. E. (2014). Effect of peer nominations of teacher-student support at individual and classroom levels on social and academic outcomes. Journal of School Psychology, 52(3), 309-322. doi: 10.1016/j.jsp.2013.12.004

Küçüker, S., Erdoğan, N.I., \& Çürük, Ç. (2014). Peer acceptance of children with disabilities in inclusive kindergarten classrooms. Pamukkale University Journal of Education, 36, 163-177.

Kurniawati, F., Minnaert, A. E. M. G., Mangunsong, F., \& Ahmed, W. (2012). An empirical study on primary school teacher's attitudes towards inclusive education in Jakarta, Indonesia. Procedia: Social and Behavioral Sciences, 69, 1430-1436. doi: 10.1016/j.sbspro.2012.12.082

Mangunsong, F. (2009). Psikologi dan pendidikan anak berkebutuhan khusus: Jilid pertama. Depok: Lembaga Sarana Pengukuran Pendidikan Psikologi (LPSP3).

Mangunsong, F. (2011). Psikologi dan pendidikan anak berkebutuhan khusus: Jilid kedua. Depok: Lembaga
Sarana Pengukuran Pendidikan Psikologi (LPSP3).

Maulipaksi, D. (2017). Sekolah inklusi dan pembangunan SLB dukung pendidikan inklusi. Diunduh dari laman Kementrian Pendidikan dan Kebudayaan:

https://www.kemdikbud.go.id/main/b log/2017/02/sekolah-inklusi-danpembangunan-slb-dukungpendidikan-inklusi

Mariyati, P. (2012). Hubungan antara traits dan teacher efficacy pada guru sekolah alam: studi pada jenjang Sekolah Dasar (Skripsi). Universitas Indonesia: Depok.

Mastroprieri, M. A., \& Scruggs, T. E. (2000). The inclusive classroom: Strategies for effective instruction. New Jersey: Prentice-Hall.

Murray, C., \& Pianta, R. C. (2007). The importance of teacher-student relationships for adolescents with high incidence disabilities. Theory Into Practice, 46(2), 105-112. doi: 10.1080/00405840701232943

Piercy, M., Wilton, K., \& Townsend, M. (2002). Promoting the social acceptance of young children with moderate-severe intellectual disabilities using cooperative-learning techniques. American Journal on Mental Retardation, 107(5), 352-360. doi: $10.1352 / 0895-$

8017(2002)107<0352:PTSAOY>2.0. Co;2

Rahmayati, F. (2013). Hubungan antara persepsi peer acceptance dan frekuensi bullying terhadap siswa penyandang Autisme Spectrum Disorder (ASD) pada siswa normal: studi di dua SMPN inklusi di Jakarta. (Skripsi). Universitas Indonesia, Indonesia.

Republik Indonesia (2003). UndangUndang Republik Indonesia Nomor 20 Tahun 2003 Tentang Sistem Pendidikan Nasional. Diunduh dari https://www.komisiinformasi.go.id/re gulasi/download/id/101 
Sigstad, H. M. H. (2017). The role of special education teachers in facilitating peer relationships among students with mild intellectual disabilities in lower secondary school. Journal of Intellectual Disabilities, 1-16. doi: $10.1177 / 1744629517715788$.

Sihombing, C.M. (2014). Hubungan antara sikap terhadap pendidikan inklusif dan strategi pengajaran pada guru $S D$ negeri dan SD swasta inklusif (Skripsi). Universitas Indonesia, Depok.

Subban, P., \& Sharma, U. (2005). Understanding educator attitudes toward the implementation of inclusive education. Disability Studies
Quarterly, 25(2), 1-19. doi: 10.18061/dsq.v25i2.545

Turnbul, A., Turnbul, R., Wehmeyer, M. L., \& Shogren, K. A. (2013). Exceptional lives: Special education in today's schools. New Jersey: Pearson.

Tschannen-Moran, M., \& Hoy, A. W. (2001). Teacher efficacy: Capturing an elusive construct. Teaching and Teacher Education, 17(7), 783-805. doi: 10.1016/S0742-051X(01)00036-1

United Nation (2008). Convention on the Rights of Persons with Disabilities (CRPD). Diunduh dari http://www.un.org/disabilities/docum ents/convention/convoptprot-e.pdf 